\title{
Educação Especial na iniciação à docência: investigação, ação e formação
}

\author{
Special education in the initiation to teaching : research, action and
}

training

La educación especial en la iniciación a la enseñanza : la investigación, la acción y la formación

\author{
${ }^{1}$ Eduardo da Luz Rocha; ${ }^{2}$ Fernando Saija de Caldas Campelo; ${ }^{3}$ Lucas da Silva Martinez; ${ }^{4} \mathrm{Me}$. \\ Everton Fêrrêr de Oliveira; ${ }^{5} \mathrm{Me}$. Jarbas Parise Moscato \\ 11du.pms@hotmail.com, Universidade Federal do Pampa; ${ }^{2}$ dinho.saija@gmail.com, \\ Universidade Federal do Pampa; ${ }^{3}$ lukasspedagogia@gmail.com, Universidade Federal do \\ Pampa; ${ }^{4}$ evertonoliveira@ unipampa.edu.br, Universidade Federal do Pampa; ${ }^{5}$ \\ jarbasmoscato@unipampa.edu.br, Universidade Federal do Pampa.
}

\begin{abstract}
Resumo
Este trabalho tem por tema a formação de profissionais para a Educação Especial através do Programa de Bolsas de Iniciação à Docência - PIBID. O objetivo do trabalho é discutirmos os fundamentos teóricos freireanos que subsidiam a formação e iniciação à docência na perspectiva freireana conforme aponta Martinez (2015), articulando com as reflexões sobre o conceito de aula, em Rays (2002), juntamente com a aprendizagem profissional da docência (MIZUKAMI, et. al., 2002) através da Investigação-Ação Educacional (CARR; KEMMIS, 1988) e a produção colaborativa de conhecimento no âmbito do PIBID a partir da Educação Dialógico-Problematizadora freireana (FREIRE, 1979, 1983, 1996, 2003). A metodologia deste trabalho parte da construção teórica dos fundamentos que subsidiam nossa ação e formação, através da revisão bibliográfica sobre os temas e a experiência pessoal dos bolsistas de iniciação à docência. Em relação à formação de professores, ressaltamos a aprendizagem profissional da docência que se torna possível através do PIBID e a investigação-ação educacional como forma potencial de melhorar o trabalho de formar professores através da reflexão sobre a própria prática, atuando na realidade e refletindo sobre ela, formando professores que relacionam teoria e prática, não dicotomizando-as. Dessa forma, alcança-se a práxis, quando se reflete sobre a prática e retornamos à teoria buscando qualificar nossa ação. Assim, é possível a produção do conhecimento através da prática, construindo então uma epistemologia da prática.
\end{abstract}

Palavras-Chave: Aprendizagem Profissional da Docência, Educação Especial, Investigação-Ação, PIBID, Produção do conhecimento.

\begin{abstract}
This work is subject to professional training for Special Education through the Fellowship Program Introduction to Teaching - PIBID. The objective is to discuss the Freire's theoretical foundations that support the training and initiation to teaching in Freire's perspective as shown by Martinez (2015), linking with the reflections on the concept of class in Rays (2002), along with professional learning teaching (MIZUKAMI, et al., 2002.) through the Educational Action-Research (CARR; KEMMIS, 1988) and the collaborative production of knowledge within the PIBID from the Education Dialogic-problematical (Freire, 197919831996 , 2003). The methodology of this study of the theoretical construction of the foundations that support our action and training, through the
\end{abstract}


literature review on the topics and personal experience of initiation scholarship to teaching. In relation to teacher education, we emphasize the professional learning of teaching made possible through PIBID and educational action research as a potential means of improving the work of training teachers through reflection on their own practice, working on reality and reflecting on her training teachers to relate theory and practice, not dichotomizing them. Thus attains praxis, when one reflects on the practice and return to the theory seeking to qualify our action. Thus, the production of knowledge is possible through practice, then building an epistemology of practice.

Keywords: Professional learning teaching, Special Education, Action-Research, PIBID, Production of knowledge.

\section{Introdução}

O Programa Institucional de Bolsas de Iniciação à Docência - PIBID, financiado pela CAPES possui subprojetos em diferentes licenciaturas. Trata-se de uma política de formação inicial de profissionais da educação com inserção de graduandos nas salas de aulas a educação básica de maneira supervisionada.

Atuamos no Subprojeto Pedagogia, pela Universidade Federal do Pampa, que é composto por três áreas temáticas, nosso trabalho situa-se na área temática Modalidades de Ensino: Educação Especial e Educação de Jovens e Adultos (EJA). Focalizamos a Educação Especial e a discussão da política sobre a EJA na escola e no município a fim de chamar a tenção ao reconhecimento da modalidade pois existem muitos jovens com 15 anos ou mais no ensino fundamental e muitos deles ligados ao atendimento educacional especializado (AEE).

Partindo dessas considerações, esclarecemos que o objetivo do trabalho é discutirmos os fundamentos teóricos freireanos que subsidiam a formação e iniciação à docência na perspectiva freireana conforme aponta Martinez (2015), articulando com as reflexões sobre o conceito de aula, em Rays (2002), juntamente com a aprendizagem profissional da docência (MIZUKAMI, et. al., 2002) através da Investigação-Ação Educacional (CARR; KEMMIS, 1988) e a produção colaborativa de conhecimento no âmbito do PIBID a partir da Educação Dialógico-Problematizadora freireana (FREIRE, 1979, 1983, 1996, 2003). A metodologia deste trabalho parte da construção teórica dos fundamentos que subsidiam nossa ação e formação, através da revisão bibliográfica sobre os temas e a experiência pessoal dos bolsistas de iniciação à docência.

Com a finalidade de organizar a leitura, dividimos as considerações teóricas que amparam nossa prática em dois blocos: primeiramente apresentamos a Educação dialógicoproblematizadora freireana e o conceito de "aula" como fundamento nas práticas na Educação Especial e posteriormente refletimos sobre Formação docente e modelos de formação: A aprendizagem profissional da docência e a investigação-ação educacional no trabalho de 
formar professores. Finalizamos considerando os implicantes na formação para a atuação na Educação Especial.

\section{Educação dialógico-problematizadora freireana e o conceito de "aula" como fundamento nas práticas na Educação Especial}

A partir da LDBEN 9394/96 que confirma a Educação Especial como uma modalidade de ensino, o poder público começa a ter iniciativas para tentar orientar e instituir diretrizes para o atendimento da educação especial, assim como delimitar seu público. Tal lei foi a primeira a afirmar no artigo 59, os sistemas de ensino assegurariam aos educandos com necessidades especiais currículos diferenciados, métodos e técnicas, recursos e também organizações adaptadas para atender às suas necessidades. (BRASIL, 1996). Em 2001, a Res. no 2 de 11 de setembro de 2001, já citada neste artigo, também pontua no art. 8 , inciso no 3 que a escola deve prover

III - flexibilizações e adaptações curriculares que considerem o significado prático e instrumental dos conteúdos básicos, metodologias de ensino e recursos didáticos diferenciados e processos de avaliação adequados ao desenvolvimento dos alunos que apresentam necessidades educacionais especiais, em consonância com o projeto pedagógico da escola, respeitada a freqüência obrigatória; (BRASIL, 2001)

Nesse sentido, o grupo partindo de análises já feitas sobre a realidade sociocultural da escola ${ }^{1}$ busca "tematizar" com elementos da realidade as adaptações curriculares de cada aluno no âmbito do Atendimento Educacional Especializado, na sala de recursos multifuncionais.

Acreditamos que o exercício da criticidade aos temas e conteúdos da realidade confronta a Educação Bancária, descrita por Freire (1987) como aquela em que os professores "depositam" conhecimentos enquanto os alunos apenas "armazenam" passivamente. Em contraposição a esta educação é necessário a busca da educação dialógico-problematizadora freireana. Pois a realidade, em sua totalidade só pode ser apreendida através da relação entre objetividade e subjetividade (FREIRE, 2006). A busca de temas para o ensino só é completa quando consegue apreender a objetividade sobre a realidade através dos alunos ou do grupo ao qual se insere.

\footnotetext{
${ }^{1}$ Ver MARTINEZ, L.; PRESTES, C.; DE OLIVEIRA, E. A investigação da realidade no contexto do PIBID: redescobrindo a investigação temática freireana. In: Anais do XVII Fórum de Estudos: Leituras de Paulo Freire [recurso eletrônico]. Instituto Federal de Educação Ciência e Tecnologia Farroupilha.- Santa Maria: IF Farroupilha, 2015
} 
Em Pedagogia da autonomia (1996) Freire aponta que a valorização dos saberes dos educandos é um dos saberes necessários à prática educativa. Para ele, pensar certo exige respeitar os conhecimentos que os alunos carregam. Exige discutir a realidade próxima dos alunos e com esta realidade articular os conceitos científicos. A "abstracidade" faz aquilo que a consciência ingênua e os opressores querem: mitificar a realidade. Quando o professor se propõe a fazer a crítica da realidade com seus alunos, torna-se um trabalhador social para a mudança (FREIRE, 1979b). Sendo assim, quando Freire propõe a investigação temática, conforme ressaltado anteriormente, na realidade concreta (apreendida através da subjetividade do pesquisador, professor, educador social, e com a visão de quem quer ajudar a educar-se), seu interesse é em problematizá-la, desvelá-la, para assim, empoderar os sujeitos para que possam se tornarem melhores, mais humanos, mais críticos, alcançar o "Ser Mais". O desafio de criar propostas curriculares atemoriza, pois demanda uma nova lógica e diálogo sobre as concepções de ensino, aprendizagem e avaliação por parte dos professores e da gestão escolar, buscando de fato incluir os estudantes com deficiência e necessidades educacionais especiais com reflexões pautadas em sua realidade. Partindo destes temores, cabe discutir o conceito de aula mediante a concepção de Rays (2002).

Para o seguinte autor, o conceito de aula vai além da compreensão de que lição é aula e que é na aula que se aprende. Para isso, exige romper estas compreensões através do conhecimento de que:

A aula preconizada pela didática crítica não comporta apenas instituições educacionais, mas também um momento político, em que os polos pedagógico e social, existentes em toda e qualquer situação de aula transformam-se em num ato relacional. A aula assume, assim, as características de um momento politcopedagógico no sentido de eliminar desse espaço político e pedagógico a ideia de que homem-objeto/aluno-objeto (submisso, obediente, acrítico) e buscar meios e condições necessários para a formação do homem-sujeito/aluno-sujeito (independente, crítico, criativo) (RAYS, 2002, p. 86)

No sentido empregado pelo autor, a aula se dá através “de um processo relacional entre o político, o pedagógico, o científico e o sociocultural (RAYS, 2002, p. 86-87)”. Dessa forma, é articulando estas dimensões que é possível a construção mediada do conhecimento, onde a dinâmica extrapola a relação professor/aluno, mas vai para além tendo como interlocutores "a ciência, o saber cotidiano, a prática social e a realidade sociocultural (p. 88)". A aula constitui-se e inicia pela ciência

(...) representada na escola pelos conteúdos programáticos, pelo educando e sua experiência sociocultural e pelas contradições sociais, porém, com um novo sentido, 
um sentido concreto que foi desvelado pelo confronto de idéias e de experiências, de proposições e de ações, tanto do educador como dos educandos, produzidos na interdependência do processo relacional educação-sociedade. (RAYS, 2002, p. 88)

A aula, ao mesmo tempo em que prepara os educandos para o desafio da vida tanto no presente quanto no futuro, precisa proporcionar condições para “a assimilação de ferramentas teórico-práticas para a intervenção no real (p. 89)". Essas ferramentas se fazem presetes no desenvolvimento de potencialidades dos sujeitos, no qual decorre "um autêntico processo de emancipação intelectual e social” (p.90), na utopia de uma construção de um projeto de sociedade igualitário e justo. Esta concepção de aula é construída a partir da compreensão da teoria socio-histórica compreendida através de Vigotski (2010) e Freire (1983), onde aprendizagem se dá através da interação e da mediatização com o mundo. Para Vigotski (2010) a aprendizagem se dá através da Zona de Aprendizagem Proximal, na qual é definida como a:

distância entre o nível de desenvolvimento real, que se costuma determinar através da solução independente de problemas, e o nível de desenvolvimento potencial, determinado através da solução de problemas sob orientação de um adulto ou em colaboração com companheiros mais capazes (VIGOTSKI, 2010, p. 97)

Através da dinâmica, da interação e da problematização é que se encontram possíveis as aprendizagens no contexto da Educação Especial em que atuamos. Rays (2002), aponta que as atividades didáticas precisam respeitar as características individuais dos alunos, o que o autor diz que nem sempre se observa na escola. De acordo com o autor:

Esse respeito é estabelecido não no sentido de minimizar a qualidade do ensino, mas no sentido de determinar o nível científico da aula para que o educando supere conscientemente suas dificuldades de aprendizagem frente ao tema de estudo. Tratase, assim de criar condições prévias para que as aulas sejam adequadas às capacidades dos alunos. Dessa forma, pode-se trabalhar o conteúdo de aula, exigindo do educando o máximo de seu conhecimento real e de suas potencialidades, com base em suas condições concretas de aprendizagem.

Esse é um modo de trabalho pedagógico que não aliena o educando e que torna o conteúdo da aula acessível à estrutura cognoscitiva do aluno, a qual, certamente, será enriquecida com a assimilação do novo conhecimento. Requer-se para tanto, que no decorrer das aulas não se secundarizem as possibilidades de os alunos desenvolverem suas capacidades e habilidades cognitivas (P.96)

\section{Formação docente e modelos de formação: A aprendizagem profissional da docência e a investigação-ação educacional no trabalho de formar professores}

A partir das reflexões levantadas a partir do conceito de aula e da educação dialógicoproblematizadora no âmbito da modalidade de ensino Educação Especial, traçamos os 
desdobramentos na perspectiva da formação docente, no que refere-se à Aprendizagem Profissional da Docência (MIZUKAMI, et. al., 2002) e na concepção de pesquisa da investigação-ação educacional (CARR; KEMMIS, 1988).

Em relação à formação docente, refletimos a seguir sobre os modelos de racionalidade técnica e racionalidade prática. Pereira (1999) critica o modelo de formação de professores chamado de racionalidade técnica. Nesse modelo segundo o referido autor, "o professor é visto como um técnico, um especialista que aplica com rigor, na sua prática cotidiana, as regras que derivam do conhecimento científico e do conhecimento pedagógico (PEREIRA, 1999, p.111-112)". Desta forma, existem um conjunto de disciplinas científicas e um conjunto de disciplinas pedagógicas, que são aplicadas no período destinado ao estágio supervisionado. Pereira aponta que:

\begin{abstract}
As principais críticas atribuídas a esse modelo são a separação entre teoria e prática na preparação profissional, a prioridade dada à formação teórica em detrimento da formação prática e a concepção da prática como mero espaço de aplicação de conhecimentos teóricos, sem um estatuto epistemológico próprio. (PEREIRA, 1999, p. 112)
\end{abstract}

Em contraposição a este modelo, surge o modelo da racionalidade prática. Segundo o referido autor, as políticas atuais de formação de professores estão caminhando ao encontro deste modelo. Segundo ele:

Por essa via, o contato com a prática docente deve aparecer desde os primeiros momentos do curso de formação. Desse envolvimento com a realidade prática originam-se problemas e questões que devem ser levados para discussão nas disciplinas teóricas (PEREIRA, 1999, p. 113).

Nesse sentido, é possível vislumbrar o Programa de Bolsas de Iniciação à Docência como um programa que pode complementar o modelo da racionalidade prática através da inserção dos bolsistas na escola pública. O PIBID é um programa que visa à formação inicial de professores para a educação básica e a formação continuada dos docentes que permanecem na escola. Esse programa é financiado pela Coordenação de Aperfeiçoamento de Pessoal de Nível Superior - CAPES.

Através dele cada bolsista tem a possibilidade de estar em contato diretamente com a escola, não deixando a responsabilidade da prática docente apenas ao período referente ao estágio supervisionado. Segundo a Portaria $n^{\circ}$ 096, de 18 de julho de 2013, são objetivos do PIBID: 
I - incentivar a formação de docentes em nível superior para a educação básica;

II - contribuir para a valorização do magistério;

III - elevar a qualidade da formação inicial de professores nos cursos de licenciatura, promovendo a integração entre educação superior e educação básica;

IV - inserir os licenciados no cotidiano de escolas da rede pública de educação, proporcionando-lhes oportunidades de criação e participação em experiências metodológicas, tecnológicas e práticas docentes de caráter inovador e interdisciplinar que busquem a superação de problemas identificados no processo de ensino-aprendizagem;

$\mathrm{V}$ - Incentivar escolas públicas de educação básica, mobilizando seus professores como conformadores dos futuros docentes e tornando-as protagonistas nos processos de formação inicial para o magistério;

VI - Contribuir para a articulação entre teoria e prática necessárias à formação dos docentes, elevando a qualidade das ações acadêmicas nos cursos de licenciatura;

VII - contribuir para que os estudantes de licenciatura se insiram na cultura escolar do magistério, por meio da apropriação e da reflexão sobre instrumentos, saberes e peculiaridades do trabalho docente. (BRASIL, 2013)

A partir dos incisos IV, VI e VII, é possível compreender as práticas do PIBID relacionadas diretamente às realidades escolares. Através do estar na escola, é possível que os bolsistas de iniciação à docência, como também os supervisores, possam estar engajados em compreender a realidade concreta que a escola insere-se e pensar ações que possam contribuir à sua mudança, sua transformação.

A partir do inciso VI, é percebida a necessidade da articulação da teoria e da prática. Pela perspectiva freireana que assumimos no grupo, as reflexões acerca da teoria e a prática são refletidas a luz da unidade dos mesmos. Sendo assim, a prática valida a teoria que é construída a partir da prática (FREIRE, 1996). Através do PIBID é possível relacionar as diversas teorias conhecidas e apreendidas no curso de formação e colocá-las em prática.

A imersão dos futuros educadores em ambientes de produção científica do conhecimento possibilita-lhes o exame crítico de suas atividades docentes, contribuindo para aumentar sua capacidade de inovação e para fundamentar suas ações. É o mergulho em tal atividade que permite a mudança de olhar do futuro docente em relação aos processos pedagógicos em que se envolve na escola, à maneira de perceber os educandos e suas aprendizagens, ao modo de conceber e desenvolver o seu trabalho em sala de aula (PEREIRA, 1999, p. 117).

Pereira (1999) aponta que é necessário formar professores que sejam reflexivos. É preciso uma junção entre a formação docente com a pesquisa e que através da postura investigativa possa surgir um professor que investigue suas próprias práticas, como na concepção de pesquisa da investigação-ação educacional.

Chamamos atenção também ao inciso VII que se refere à inserção na cultura escolar do magistério, por meio da apropriação e reflexão sobre o trabalho docente. O contato direto 
que os bolsistas de iniciação à docência têm com a escola lhes permite refletir sobre a realidade concreta das escolas, seu funcionamento e os saberes necessários ao professor.

Neste sentido a vivência no PIBID no percurso formativo da licenciatura em pedagogia pode ser considerada como investigação da realidade enquanto "questionamento reconstrutivo" (DEMO, 2011). Produz um questionar constante, em busca de saber fazer, e de refazer constantemente sua competência, utilizando a pesquisa e o seu pensamento como atitude efetiva, esse profissional se torna autêntico. Nas palavras de Demo (2011) "Ele tem capacidade de inovar, questionar suas práticas, estando na vanguarda. Ele puxa a vanguarda. Refaz sua profissão" (p. 85).

A partir destes pressupostos em relação ao programa e o modelo de racionalidade prática, encontra-se a aprendizagem profissional da docência. Para Mizukami et. al., (2002, p. 12):

\begin{abstract}
Aprender a ser professor nesse contexto, não é, portanto, tarefa que se conclua após estudos de um aparato de conteúdo e técnica de transmissão deles. É uma aprendizagem que deve se dar por meio de situações práticas que sejam efetivamente problemáticas, o que exige o desenvolvimento de uma prática reflexiva competente. Exige ainda que, além de conhecimentos, sejam trabalhadas atitudes, as quais são consideradas tão importantes quanto os conhecimentos.
\end{abstract}

Dessa forma, a docência é constituída através da relação entre teoria e prática, do entrelaçamento destas condições, sendo elas necessárias para que haja a reflexão, conectada a realidade do fazer docente, em um contexto de práxis, ação-reflexão-ação. É da investigação da prática que é possível reconstruir seu fazer. Assim,

[...] aprender a ensinar é desenvolvimental e requer tempo e recursos para que os professores modifiquem suas práticas; que as mudanças que os professores precisam realizar de formar a contemplar novas exigências sociais e de políticas públicas vão além do aprender novas técnicas, implicando revisões conceituais do processo educacional e instrucional e da própria prática (MIZUKAMI et. al., 2002, p. 44).

Ibiapina (2008) contribui a esta reflexão quando afirma que no processo de reconstrução, as significações elaboradas ultrapassam o espaço de compreensão existente, penetrando no sistema conceitual já elaborado pelo docente, fazendo que evolua em suas práticas. É na reflexividade que "o professor mergulha na prática e traz à tona a teoria para compreender de forma mais clara os conceitos que guiam a atividade docente. Assim, ao passar da reflexão com base no texto à análise da ação prática, é possível reconstruí-la (p. 47)". 
De acordo com Borges (2004) essa reconstrução se dá a partir das primeiras vivências práticas. Assim “Quando começam a ensinar, os professores vão, aos poucos, percebendo que os conhecimentos disciplinares e proposicionais de formação inicial não respondem a todas as demandas da realidade, às exigências dos alunos e do cotidiano escolar (p. 270)".

Assim, pensar um contexto de investigação de práticas, através do fazer docente em constante ação-reflexão-ação exige pensar uma concepção de investigação que predomine seu campo de investigação na ação. Dessa forma, concebemos a investigação-ação educacional como forma possível de formar professores através da reflexão sobre sua ação.

Carr e Kemmis (1988) definem a investigação-ação como “(...) uma forma de indagação autorreflexiva que os participantes em situações sociais empreendem em situações sociais em ordem a melhorar a racionalidade e a justiça de suas próprias práticas (p. 174, tradução nossa).”. Para eles, a investigação-ação se configura como uma "ciência educacional crítica".

Através da investigação-ação promove-se o desenvolvimento profissional dos participantes, refletindo sobre sua prática, tornando-a mais eficaz e produtiva, a qual confere um protagonismo maior aos profissionais, em nosso caso, professores (BRAVO e EISMAN, 1994, p. 292). A investigação-ação se configura uma concepção de pesquisa, porque enquanto concepção, aceita diversos métodos, entre eles o estudo de caso, a pesquisa de cunho sócioantropológico, a pesquisa etnográfica, entre outras, assim como também a utilização de diversos instrumentos de coleta de dados, tais como: entrevistas, diários, questionários, gravações e etc.

Segundo Carr e Kemmis (1988), a investigação-ação foi criada por Kurt Lewin, na década de 40. Segundo os mesmos autores, essa concepção é a preferencial quando se refere a investigações relativas às práticas sociais. Essa concepção de investigação se baseia "em uma espiral autorreflexiva formada por ciclos sucessivos de planejamento ação, observação e reflexão (p. 174, tradução nossa)".

Nesse sentido a investigação-ação é então uma ferramenta e uma estratégia para estabelecer a capacidade de diálogo problematizador com as diferentes condições concretas, os diferentes contextos, os diferentes sujeitos que interagem na situação educativa. Ao mesmo tempo que a investigação transforma as práticas de ensino em práticas de ensino investigativas ampliando o universo do conhecimento educacional. (DE OLIVEIRA, 2005, p. 106)

Conforme De Bastos e Grabauska (1998), quando a investigação-ação é planejada e praticada, ela "pode auxiliar os seres humanos a interpretar a realidade a partir de suas 
próprias práticas, concepções e valores. Aí está um potencial transformador bastante grande (p.5)" Para completar, Grabauska (2006) afirma que associar a investigação com a prática docente é "uma maneira de recuperar o poder profissional dos professores (p. 45)".

Dentro, os quatro ciclos que fazem parte desta "espiral autoreflexiva lewiniana", descrevemos sucintamente cada ciclo:

1. Planejamento: A partir das vivências naquela realidade, pensa-se em um plano de ação, uma atividade, uma experiência.

2. Ação: Coloca-se em prática o planejamento pensado.

3. Observação: Os participantes deste processo observam tudo aquilo que lhes podem ser indicadores de falha, de êxito, problemáticas que precisam ser discutidas, entre outras situações;

4. Reflexão: A partir do planejamento, da ação e da observação, pensa-se no na natureza do processo, os condicionantes, o que possibilitou o êxito ou o fracasso, e por consequente, produzem subsídios para um novo planejamento, e dessa forma o ciclo continua.

Figura 1 - Ciclos da investigação-ação

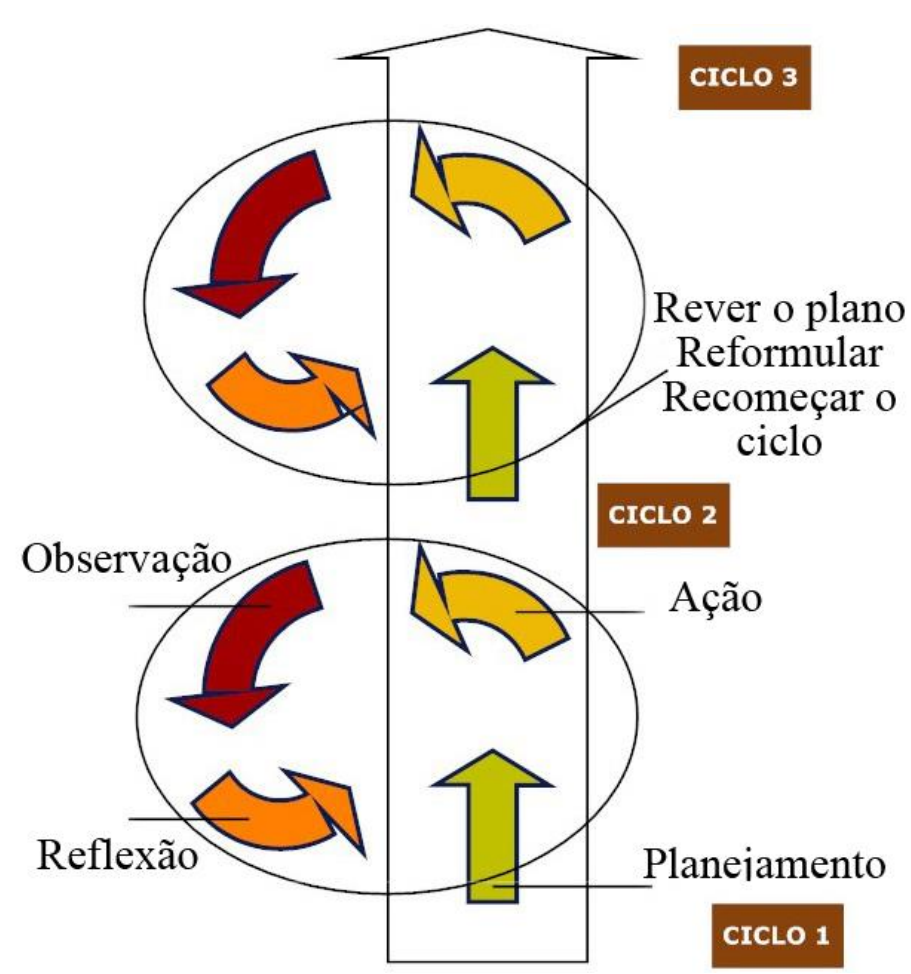

Fonte: Baseado em Carr e Kemmis (1988) 
Assim, através dos sucessivos ciclos de planejamento, ação, observação e reflexão, os professores, podem em sua prática refletir, compreendê-la para assim transformá-la, recuperando poder profissional e desenvolvendo-se profissionalmente, em um contexto de ação-reflexão-ação, em uma epistemologia da prática.

\begin{abstract}
Essa nova perspectiva em termos metodológicos articular bem a teoria e a prática e apresenta diferenças contrastantes com os métodos científicos mais ortodoxos. Seus diferentes enfoques, no geral, enfatizam a manifestação de construções da realidade por meio das "ações ou práticas reflexivas" das pessoas e comunidades. O conhecimento surge na e para a ação e a teoria é sistematicamente testada em contextos reais. Supõe-se que uma das primeiras implicações de uma tal epistemologia da ação seja uma mudança na experiência vivida daqueles envolvidos no processo de questionamento/reflexão/investigação; experiência que conduz a novos conhecimentos por meio da participação." MIZUKAMI et al., 1998, p.97 apud MIZUKAMI et al., 2002, p. 141
\end{abstract}

\title{
4. Considerações finais
}

Consideramos ser pertinente a compreensão das novas realidades educacionais e sociais, apoiada nas áreas dos conhecimentos escolares pode ampliar a visão de abrangência das demandas e possibilidades dessas práxis para além dos das dificuldades atribuídas aos alunos, mas, voltada a práticas sociais mais amplas e o professor caracterizado como mediador sociopedagógico. É importante que os profissionais desenvolvam uma percepção do ato educativo em complexidade, com conhecimentos capazes de explicitar os processos de ensinar e aprender e, ainda, dos múltiplos recursos tecnológicos disponíveis como apoio à dinamização da práxis pedagógica. Através da explicitação do conceito de aula e as dimensões pedagógica, política, científica e sociocultural que é possível pensar ações que englobem tais dimensões e qualifiquem o processo educativo para além da reprodução, mas para a emancipação.

Em relação à formação de professores, ressaltamos a aprendizagem profissional da docência que se torna possível através do PIBID e a investigação-ação educacional como forma potencial de melhorar o trabalho de formar professores através da reflexão sobre a própria prática. Outro ponto a ser mencionado é em relação à carga horária destinada na formação docente para atender públicos específicos como, por exemplo, a Educação especial, Educação jovens e adultos, Educação do Campo e etc. A grade curricular oferecida nas universidades contemplam muito pouco estas modalidades de ensino, tornando o programa de iniciação à docência, na perspectiva das modalidades de ensino, fundamental para complementar a formação. É uma oportunidade de conhecer a realidade vivida diariamente no ambiente escolar, o compartilhamento de experiências, conhecimentos e ideias entre os 
educadores, bolsistas, supervisores, orientadores, alunos e equipe gestora da escola. Formar professores para a Educação Especial é uma necessidade emergente, visto o contexto de políticas que buscam ampliar a oferta e qualificá-la, na perspectiva da Educação Inclusiva, através da mediação em sala de aula e o Atendimento Educacional Especializado (AEE). Neste sentido, as discussões e nossas práticas se encaminham para a efetivação dessa formação através da ação na Educação Especial (MARTINEZ; DE OLIVEIRA; MOSCATO, 2015, no prelo)

Assim, concluímos o texto apontando caminhos diferenciados à formação de professores através das teorias acima relacionadas. Vislumbramos a racionalidade prática e a inserção dos bolsistas na escola, atuando na realidade e refletindo sobre ela, formando professores que relacionam teoria e prática, não dicotomizando-as. Dessa forma, alcança-se a práxis, quando se reflete sobre a prática e retornamos à teoria buscando qualificar nossa ação. Assim, é possível a produção do conhecimento através da prática, construindo então uma epistemologia da prática.

\section{Referências}

BORGES, Cecília Maria Ferreira O Professor da Educação Básica e seus Saberes Profissionais. Araraquara, Editora : JM, 2004

BRASIL. Portaria $\mathbf{n}^{\circ}$ 096, de 18 de julho de 2013 - Aprova as normas do Programa Institucional de Bolsa de Iniciação à Docência - Pibid. Disponível em: <http://www.capes.gov.br/educacao-basica/capespibid>. Acesso em abril de 2013.

Conselho Nacional de Educação. Câmara de Educação Básica. Resolução CNE/CEB no 02, de 11 de setembro de 2001. Diretrizes Nacionais para a Educação Especial na Educação Básica. Diário Oficial da União, 14 de setembro de 2001.

Lei de Diretrizes e Bases da Educação Nacional. Lei no 9.394, de 20 de Dezembro de 1996. Disponível em: 〈http://portal.mec.gov.br/arquivos/pdf/ldb.pdf>. Acesso em: Maio de 2013.

BRAVO, Maria. P. C; EISMAN, Leonor. B. Investigación Educativa. Alfar, Sevilla, 1994

CARR, Wilfred.; KEMMIS, Stephen. Teoría crítica de la enseñanza: La investigaciónacción en la formación del professorado. Barcelona: Ediciones Martínez Roca S.A, 1988.

DEMO, Pedro. Educar pela pesquisa. 9 ed. revista - Campinas, SP: Autores Associados, 2011 (Coleção educação contemporânea)

DE BASTOS, Fábio; GRABAUSKA, Clayton. J. Investigação-Ação Educacional: possibilidades críticas e emancipatórias na prática educativa. In: Heuresis Revista 
Electrónica de Investigación Curricular y Educativa, vol.1, n.2, 1998. Cadiz, España. Disponível em: <http:/www2.uca.es/HEURESIS>, Acesso em: fevereiro/2015

DE OLIVEIRA, Everton. F. Processos cíclicos do desenvolvimento profissional: para além de métodos e procedimentos acadêmicos. In: CADERNOS DE ENSINO, PESQUISA E EXTENSÃO. IX Escola de Investigação-ação (EIA): Conflitos e desafios. Centro de Educação, Laboratório de Pesquisa e Documentação LAPEDOC. Santa Maria, 2005.

FREIRE, Paulo. Pedagogia do Oprimido. 16a ed. Rio de Janeiro: Paz e Terra, 1983

Criando métodos de pesquisa alternativa: aprendendo a fazê-la melhor através da ação. In: BRANDÃO, C. R (org). Pesquisa participante. São Paulo: Brasiliense, 2006

. Educação e mudança. Rio de Janeiro: Paz e Terra, 1979

. Pedagogia da autonomia: saberes necessários à prática educativa. São Paulo: Paz e Terra, 1996 (Coleção Leitura)

GRABAUSKA, Clayton. J. Educação Problematizadora e Formação de professores no Contexto Universitário. In: Aprimorando-se com Paulo Freire... no Quefazer Educativo. Recife, PE: Bagaço, 2006

IBIAPINA, Ivana Maria Lopes de Melo. Pesquisa colaborativa: Investigação, formação e produção de Conhecimentos. Editora : Líber Livro Editora, 2008.

MARTINEZ, Lucas da S. Iniciação à Docência: reflexão sobre a prática docente em uma perspectiva freireana. 2015, 55 f. Trabalho de conclusão de curso (Licenciatura em Pedagogia) - Universidade Federal do Pampa, Jaguarão.

; DE OLIVEIRA, Everton Fêrrer; MOSCATO, Jarbas Parise. Inclusão de alunos com deficiência: alguns apontamentos. Diálogo, Canoas, n. 30, Unilassale, 2015. No prelo.

MIZUKAMI, M. et al. Escolas e aprendizagem da docência: processos de investigação e formação. São Carlos: EdUFSCar, 2002.

PEREIRA, Júlio. E. D. As licenciaturas e as novas políticas educacionais para a formação docente. Educ. Soc., Campinas , v. 20, n. 68, p. 109-125, Dec. 1999. Disponível em: $<$ http://www.scielo.br/scielo.php?script=sci_arttext\&pid=S0101-

$73301999000300006 \& \operatorname{lng}=\mathrm{en} \& n r m=i s o>$. Acesso em: 21 jun. 2015.

RAYS, Oswaldo Alonso. O conceito de aula: um dos saberes necessários à práxis pedagógica. In: RAYS, Oswaldo Alonso (org.). Educação: ensaios reflexivos. Editora Pallotti, Santa Maria, RS, 2002

VIGOSTSKI, Lev S. A formação social da mente. São Paulo: Martins Fontes, 2010. 